\title{
EFEITOS DA UTILIZAÇÃO DO PLASMA SUÍNO SECO NA ALIMENTAÇÃO DE LEITÕES DESMAMADOS AOS 17 DIAS DE IDADE
}

\author{
Bruno de Souza Mariano ${ }^{1}$ \\ Jurij Sobestiansky ${ }^{2}$ \\ Euripides Laurindo Lopes ${ }^{2}$ \\ Otto Mack Junqueira ${ }^{3}$
}

Resumo

O presente estudo teve como objetivo avaliar os efeitos da utilização de níveis crescentes de plasma suíno seco na dieta sobre o desempenho e a incidência de diarréias em leitões desmamados aos 17 dias de idade. Foram utilizados 200 leitões, da linhagem Agroceres, em uma GSMD (granja de suínos com mínimo de doenças), com quatro tratamentos e cinco repetições por tratamento, sendo 10 leitões por unidade experimental, e metade de cada sexo. Os níveis de inclusão de plasma seco foram: 0\%, 2\%, 4\% e 6\%. O delineamento experimental foi o inteiramente casualizado e os resultados analisados por meio da análise de variância, utilizando-se o programa SAEG. A adição do plasma de suíno seco por spray-dryer em rações de leitões após o desmame não influenciou o desempenho nem a incidência de diarréia em leitões de 21 a 42 dias de idade.

Palavras-chave: Desempenho, Desmame, Diarréia, Plasma suíno seco, Suíno.

\section{Abstract}

The present experiment was conducted to evaluate the effects of increasing levels of spray-dried porcine plasma (SDPP) in the diet on the performance and on the incidence of diarrehea of pigs weaned at 17 days of age. Two hundred animals from the Agroceres line were used in a minimal disease, with 4 treatments and 5 repetitions per treatment, each experimental unit consisting of 10 suckling pigs, half of each sex. The levels of plasma studied were 0, 2, 4 and 6\%. A completely randomized design was used and the analysis of variance was done using the SAEG program. The addition of spray-dried porcine plasma in the ration of weaned pigs did not influence their performance or the incidence of diarrhea in animals between 21 and 42 days of age.

Keywords: Diarrhea, Performance, Swine, Spray-dryed porcine plasma (SDPP), Weaning.

1 Departamento de Zootecnia - UCG - Av. Universitária, 1440, St. Universitário CEP 74.605 - 010 Goiânia - GO E-MAIL: mariano@cultura.com.br

2 Escola de Veterinária - Produção Animal - UFG - Campus II Samambaia CEP 74.001 - 970 Goiânia - GO

3 Departamento de não ruminantes - FCAV - UNESP/Jaboticabal 


\section{Introdução}

A suinocultura vem, ao longo do tempo, desenvolvendo-se e buscando um mercado cada vez mais especializado, devido à grande demanda de carne suína. Assim, por ser a carne mais consumida e produzida mundialmente, tem um papel fundamental no crescimento acelerado da população mundial. O mundo contava no ano de 2000 com uma população estimada em 5.950 milhões de pessoas, número que pode dobrar nos próximos 100 anos. Na crescente necessidade da população mundial, no que se refere à proteína animal de alta qualidade, a suinocultura é a principal atividade a ser considerada (ROPPA, 2000).

O complexo sistema de produção de suínos (SPS), deve necessariamente ser administrado técnica e economicamente como uma empresa, o que requer de seu proprietário, juntamente com sua equipe (Responsável técnico, gerente, chefe de setores e demais funcionários), a tomada de decisões com normas e procedimentos que possam garantir sempre o sucesso do empreendimento, que passa necessariamente pela garantia de índices zootécnicos sempre acima dos alvos estabelecidos, que serão expressos em lucratividade.

Ao contrário do que ocorre em condições naturais, quando o desmame é um processo gradual, sem mudanças dramáticas, o desmame precoce é um dos momentos mais críticos para os leitões, em que vários fatores concorrem para causar estresse nos animais, tais como separação da mãe, mudança de ambiente, deficiência no controle ambiental, dificuldade de adaptação a comedouros e bebedouros, misturas de leitões de outras leitegadas e troca de dieta, tudo isso leva à queda da imunidade e redução do consumo, favorecendo a manifestação de doenças e reduzindo a taxa de crescimento.

O período de 21 dias após o desmame é considerado uma fase crítica na produção de leitões, devido à ocorrência simultânea de vários fatores estressantes, principalmente relacionados com a separação, a mudança brusca de alimentação, a mudança de ambiente e a mistura de leitões para formação de lotes na creche. Conseqüentemente, alguns problemas sanitários, como síndrome da diarréia pós-desmame e a doença do edema, podem surgir, ocasionando perdas econômicas pela elevação da taxa de mortalidade e pela redução no ganho de peso dos leitões afetados (MORÉS et al. 1990).
O presente estudo teve como objetivo avaliar os efeitos da utilização do plasma suíno seco na alimentação de leitões desmamados aos 21 dias de idade, considerando o desempenho e a incidência de diarréias.

\section{Material e métodos}

O experimento foi conduzido na Granja Indiara, considerada granja GSMD, situada no município de Indiara, Estado de Goiás. Foram utilizados 200 leitões, da linhagem Agroceres, desmamados com idade média de 17 dias, sendo a metade de cada sexo.

O experimento teve a duração de 21 dias, por ocasião da transferência da maternidade para creche, onde os animais foram examinados clinicamente, segundo metodologia descrita por Plonait, (1997); Soncini E Madureira, (1998), utilizando-se apenas aqueles livres de sinais clínicos de onfalite, diarréias, artrite, tosse, espirros e alterações na pele.

Nos quatro primeiros dias após o desmame, foram fornecidas aos leitões as rações experimentais e considerou-se este como período de adaptação. Foram utilizadas duas salas de creche, as quais, antes da introdução dos leitões, foram lavadas e limpas conforme recomendado por Sobestiansky (1998). As rações foram fornecidas 3 vezes ao dia, de modo que não houvesse falta, nem fornecimento em excesso, evitando-se o desperdício e estimulando os animais ao consumo da ração.

O delineamento experimental utilizado foi o inteiramente casualizado, com quatro tratamentos, cinco repetições por tratamento e 10 leitões por unidade experimental. Os tratamentos foram os seguintes: T1- milho + farelo de soja + óleo degomado + núcleo; T2- milho + farelo de soja + óleo degomado + núcleo $+2 \%$ de plasma; T3- milho + farelo de soja + óleo degomado + núcleo $+4 \%$ de plasma; T4- milho + farelo de soja + óleo degomado + núcleo + 6\% de plasma.

As rações utilizadas foram formuladas à base de milho e farelo de soja com pesagem e mistura dos ingredientes realizadas na fábrica de ração da própria granja. Os resultados foram analisados através da análise de variância, utilizando-se o programa SAEG (Sistema de Analises Es- 
tatísticas e Genéticas, versão 2000), desenvolvido por Euclides (1987). As características zootécnicas avaliadas foram o ganho de peso (GP) $(\mathrm{kg})$, o consumo de ração (CR) (kg), o índice de conversão alimentar (CA) e a incidência de diarréias. Para análise do ganho de peso da conversão alimentar e consumo de ração, os animais foram pesados no inicio e final do experimento, a ração consumida pelos animais foi pesada, sendo que ao final do experimento a ração não consumida foi descontada do total. Para avaliação da incidência de diarréia, os leitões foram observados duas vezes ao dia: às $9 \mathrm{~h}$ e às 16h, bem como visualmente suas fezes, quando o leitão defecava ou diretamente na ampola retal, classificando-as da seguinte maneira (Soncini \& Madureira, 1998)): $0=$ fezes normais (firmes); $1=$ fezes amolecidas; $2=$ fezes líquidas; 3 = fezes líquidas e animais desidratados. Quando mais de 20\% dos animais apresentaram diarréias, o lote foi considerado com incidência de diarréia. Com relação à severidade da diarréia o lote foi classificado da seguinte forma: nenhum dia com diarréia/ semana = lote sem diarréia; um a três dias com diarréia/semana = lote com pouca diarréia; quatro ou mais dias com diarréia/semana $=$ lote com bastante diarréia.

\section{Resultados e discussão}

Na Tabela 1 verifica-se que os resultados médios das características de desempenho representadas pelos pesos inicial e final $(\mathrm{kg}), \mathrm{CR}$, GP e CA dos leitões no período de 21 a 42 dias de idade, alimentados com níveis diferentes de inclusão de plasma seco, não foram estatisticamente diferentes $(\mathrm{P}>0,05)$, isso contraria os resultados obtidos por BUTOLO et al., 1999; RODAS et al., 1995, que encontraram diferenças significativas em estudos de inclusão de plasma na alimentação de leitões ao desmame. Estes afirmaram que o aspecto sanitário do ambiente influencia no desempenho dos animais, ou seja, em ambiente com aspectos sanitários bons, a resposta à ação do plasma não foi satisfatória; em contrapartida, em ambientes nos quais o nível sanitário foi ruim, a ação do plasma foi significativamente superior ao tratamento que não tinha inclusão. As proteínas do plasma têm sido estuda- das intensivamente nos últimos anos, porém não se sabe ao certo os mecanismos específicos do modo de ação (BUTOLO et al., 1999). Observase que quanto maior o desafio ambiental, mais consistente parece ser a resposta positiva da inclusão do plasma. Goihl (1996) afirmou em estudos, contribuindo para a discussão, que as razões para a melhoria do desempenho de leitões alimentados com dietas contendo plasma ainda permanecem como não esclarecidas. BERGSTRÖN et al. (1997) confirmaram, após estudos, que a ação do plasma na dieta de leitões recém-desmamados criados em ambientes convencionais sofreu influência positiva no desempenho, enquanto que para ambiente limpo sua ação não teve nenhuma interferência. A temperatura média observada não apresentou variações, sendo que a média diária da temperatura e da umidade foi respectivamente $26,8^{\circ} \mathrm{C}$ e $73,5 \%$, permanecendo então dentro da temperatura considerada como ideal, de acordo com OLIVEIRA, 1999, que definiu como ideal para os leitões na primeira semana após o desmame a temperatura de 28 a $30^{\circ} \mathrm{C}$.

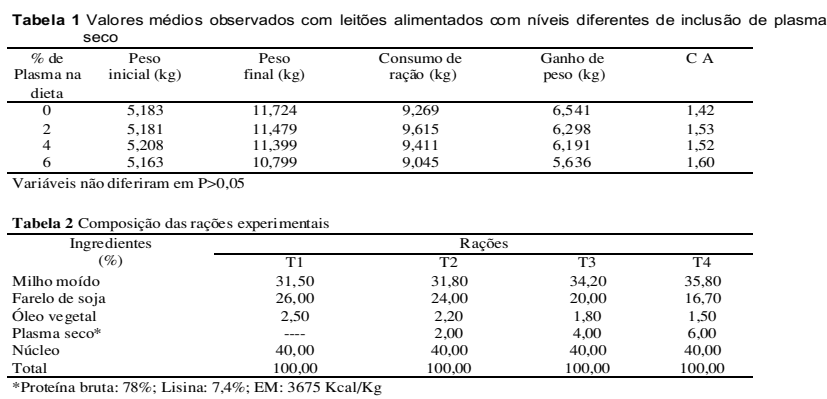

\section{Conclusões}

Nas condições em que foi realizado o experimento, pode-se concluir que a adição do plasma de suíno seco por spray-dryer em rações de leitões ao desmame não influenciou no desempenho, nem na incidência de diarréia de leitões dos 21 aos 42 dias de idade.

\section{Agradecimentos}

Agradecemos a Vacinar Nutrição e Saúde Animal, Indústria, Comércio, Exportação e Importação ICC e Associação Goiana de Suinocultores (AGS) pela colaboração. 


\section{Referências}

BERGSTRÖN, J.R. et al. Evaluation of spray-dryer animal plasma and select menhaden fish meal in transition diets of pigs weaned at 12 to 14 days of age and reared in different production systems. $\mathbf{J}$. Anim. Sci Champaign, v.75, n.11, p.3004-3009, 1997.

BUTOLO, E.A F., MIYADA, V. S., PACKER, I.U., et $a l$., Uso de plasma suíno desidratado por "spray dryer" na dieta de leitões desmamados. Rev. Bras.

Zoot., v.28, n.3, p.326-333, 1999.

EUCLIDES, R.F. Manual de utilização do programa SAEG (versão 2000) Sistema para Análises Estatísticas e Genéticas. Viçosa: CPD-UFV, 1987.

MORÉS, N.; MARQUES, L-L.J; SOBESTIANSKY, J. et al. Influência do nível protéico e/ou da acidificação da dieta sobre a diarréia pós-desmame em leitões causada por Escherichia coli. Pesq. Vet. Bras., v.10, p.85-88, 1990.
PLONAIT, H. Der Tierarzt in Schuvimebestand. In: PLONAIT, H. BICKHARDT, Klehbruch der Schuvimebestand. 2 ed. Parey Buchverlag, 1997.

ROPPA, L. Estatísticas da suinocultura mundial. 2000, Disponível em: http://www.porkworld.com.br Acesso em: 30 Jun. 2000.

SOBESTIANSKY, J. et al. . Suinocultura intensiva: Produção, manejo, e saúde do rebanho. Concórdia: EMBRAPA:CNPSA, 1998.

SONCINI, R.A; MADUREIRA, S.E.J. Monitorias sanitárias. Cap.5. In: SOBESTIANSKY, J.; WENTZ, I.; SILVEIRA, P. R. S. da; SESTI, L. Suinocultura intensiva: produção, manejo e saúde do rebanho. Brasília: EMBRAPA, 1998. 